\title{
PENERAPAN ALGORITMA NEURAL NETWORK BACKPROPAGATION DALAM MENGIDENTIFIKASI PASIEN BERISIKO DISLIPIDEMIA
}

\author{
Nuraida Latif ${ }^{1),}$ Andi Yulia Muniar ${ }^{2)}$, Muh Nuhwaqif ${ }^{3)}$ \\ 1)23) Program Studi Teknik Informatika \\ STMIK AKBA \\ Jl. Perintis Kemerdekaan, Makassar Sulawesi Selatan \\ ${ }^{1}$ nuraidah.akba@gmail.com
}

\begin{abstract}
ABSTRAK
Penelitian ini bertujuan merancang sistem untuk mengidentifikasi pasien berisiko dislipidemia menggunakan Algoritma Neural Network Backpropagation.Metode yang digunakan untuk menganalisis permasalahan dalam penelitian ini adalah dengan studi pustaka, perumusan masalah, mengumpulkan dan mengolah datadata penelitian, merancang sistem, membuat sistem, menguji sistem, dan penarikan kesimpulan. Pada penelitian ini dataset yang digunakan sebanyak 346 data sampel yang dibagi menjadi data training dan data testing, rasio pembagian untuk data training dan data testing adalah $80 \%: 20 \%$. Metode dalam pemilihan data training dan data testing dilakukan dengan cara acak. Pada pelatihan data training digunakan data sebanyak 277 data (80\%), dan pada pengujian data testing digunakan data sebanyak 69 data (20\%). Hasil penelitian ini menunjukkan bahwa Algoritma Neural Network Backpropagation dapat digunakan untuk mengidentifikasi pasien berisiko dislipidemia. Dalam pengujian sistem dengan 69 data testing $(20 \%)$ di dapatkan hasil akurasi sebesar $86,96 \%$.
\end{abstract}

Kata Kunci : Neural Network, Backpropagation, Dislipidemia

\begin{abstract}
This study aims to design a system to identify dyslipidemia using Backpropagation Neural Network Algorithm.The method used for this study is literature study, problem formulation, collecting and processing research data, then creating systems, creating systems, testing systems, and reducing conclusions.In this study, the dataset used was 346 sample data which were divided into training data and testing data, the distribution ratio for training data and testing data was 80\%: 20\%. Methods in selecting training data and testing data are done in a random way. In training data training used 277 data (80\%), and on testing data testing used 69 data (20\%). The results of this study indicate that the Backpropagation Neural Network Algorithm can be used to identify patients at risk for dyslipidemia. In testing the system with 69 testing data (20\%), the accuracy result is $86.96 \%$.
\end{abstract}

Keywords : Neural Network, Backpropagation, Dyslipidemia 


\section{PENDAHULUAN}

Menurut data dari pusat data dan informasi kementerian kesehatan RI tahun 2014, penyakit tidak menular (PTM) mengakibatkan kematian lebih dari 36 juta orang atau sekitar $63 \%$ dari seluruh total kematian. Dan secara global penyakit yang banyak merenggut jiwa adalah cardiovascular. Penyakit cardiovascular merupakan penyakit yang yang disebabkan oleh adanya kelainan pada pembuluh darah dan fungsi jantung, seperti penyakit jantung koroner, gagal jantung, hipertensi dan stroke. Dislipidemia sendiri adalah suatu kelainan yang disebabkan terganggunya metabolisme lipid akibat interaksi faktor genetik dan faktor lingkungan atau yang ada kaitannya dengan meningkatnya kadar konsentrasi low density lipoprotein (LDL), kolesterol total dan trigliserida (VLDL) serta penurunan kadar High density lipoprotein (HDL) maupun kombinasi dari ketidaknormalan tersebut dan juga dalam tubuh dislipidemia Dislipidemia tidak menunjukkan gejala sehingga sulit dideteksi secara fisik. namun jika seseorang sudah terkena dislipidemia,resiko terkena penyakit jantung koroner akan meningkat drastis. (Hayudanti dkk, 2016).

Pencegahan terhadap faktor yang dapat dimodifikasi perlu ditingkatkan dalam hal ini penanganan terhadap dislipidemia. Dislipidemia dapat terjadi karena adanya peningkatan hipercholesterolemia dan hipertrigliserida sebagai faktor utama dan juga terhadap faktor-faktor lainnya yang mempengaruhi adanya kemungkinan dislipidemia.

Sehingga diperlukan suatu metode untuk mengklasifikasi faktor-faktoryang menjadi penyebab dislipidemia supaya pencegahan dapatdilakukan dengan lebih efisien. Dan salah satu metode yang dapatdigunakan adalah teknik klasifikasi data mining.

Jaringan syaraf tiruan merupakan sistem pemrosesan informasi yangmemiliki karakteristik kemampuan yang secara umum mirip dengan jaringan syarafbiologi. Jaringan Syaraf Tiruan Backpropagation adalah suatu model jaringan syaraftiruan yang paling sering dipakai karena memiliki unjuk kerja yang baik dari sisitingkat ketelitiannya. Selain itu, jaringan ini juga memiliki kemudahan dalam melakukan pelatihan (Siang, 2009).

Agus Nurkhozim dkk dalam penelitiannya yang berjudul komparasimetode klasifikasi penyakit diabetes militus dengan menggunakan jaringan syaraftiruan Learning Vector Quantization (LVQ)dan backpropagation, dengan perbandingan antara metode Learning Vector Quantization (LVQ) dan backpropagation yang menghasilkan tingkat akurasi yang didapatkan dalam penelitiannya yaitu dengan nilai akurasi rata-rata menunjukkan $97.7 \%$. Hasil inididapatkan dari uji coba running program dengan mentraining sebanyak 345 datadengan menggunakan learning rate $=0.01$ (menggunakan metode LVQ)sedangkan nilai rata-rata persentase keakurasian yang ditinjau dari banyak iterasiadalah 99.2\%. Hasil ini didapatkan dari uji coba running program denganmentraining sebanyak 345 data (menggunakan metode Backpropagation). Sehingga perbandingan tingkat akurasi dengan ditinjau dari mengkombinasikannilai learning rate ini, metode Backpropagation mempunyai tingkat akurasi lebih tinggi jika dibandingkan metode Learning Vector Quantization (LVQ).

\section{LANDASAN TEORI}

\subsection{Penyakit Dislipidemia}

Dislipidemia didefinisikan sebagai kelainan metabolisme lipid yang ditandai dengan peningkatan maupun penurunan fraksi lipid dalam plasma. Kelainan fraksi lipid yang utama adalah kenaikan kadarkolesterol total $(\geq 240 \mathrm{mg} / \mathrm{dl})$, Low Density Lipoprotein (LDL) $(\geq 160 \mathrm{mg} / \mathrm{dl})$, dan trigliserida $(\geq 200 \mathrm{mg} / \mathrm{dl})$ serta penurunan kadar High Density Lipoprotein (HDL) $(<40 \mathrm{mg} / \mathrm{dl})$.

Menurut Eropean Atherosclerosis Society (EAS) dislipidemia diklasifikasikan secara klinis menjadi tiga, yaitu:hypercholesterolemia atau kolesterol tinggi yang kaitannya pada meningkatnya kadar kolesterol total, hypertrigliserida yaitu kadartrigliserida yang melebihi batas normal, dan campuran antara hypercholesterolemia dan hypertrigliserida (dyslipidemia campuran).

Batasan kadar resiko dislipidemia setiap orang berbeda- beda, sehingga tidak dapat menerapkan batasan kadar salah satu orang kepada orang lainnya. Sehinggga dibuatlah suatu batasan yang bersifat umum yang dapat dipakai semua orang tanpa melihat faktor resiko koroner yang telah disahkan oleh National Cholesterol Education Program Adult Treatment Panel III (NCEP ATP III) pada tahun 2001. Berdasarkan patologinya, dislipidemia ada 2, yaitu dislipidemia primer dan dislipidemia sekunder.

\section{a. Dislipidemia primer}

Dislipidemia primer adalah dislipidemia akibat kelainan genetik. Pasien dislipidemia sedang disebabkan oleh hiperkolesterolemia poligenik dan dislipidemia kombinasi familial .Dislipidemia berat umumnya karena hiperkolesterolemia familial, dislipidemia remnan, dan hipertrigliseridemia primer.

\section{b. Dislipidemia sekunder}

Pengertian sekunder adalah dislipidemia yang terjadi akibat suatu penyakit lain misalnya hipotiroidisme, sindroma nefrotik, diabetes melitus, dan sindroma metabolik. Pengelolaan penyakit primer akan memperbaiki dislipidemia yang ada. Dalam hal ini pengobatan penyakit primer yang diutamakan. Akan tetapi pada pasien diabetes mellitus pemakaian obat hipolipidemik sangat dianjurkan, sebab risiko koroner pasien tersebut sangat tinggi. Pasien diabetes melitus dianggap 
mempunyai risiko yang sama (ekivalen)dengan pasien penyakit jantung koroner. Pankreatitis akut merupakan menifestasi umum hipertrigliseridemia yang berat.

\subsection{Neural Network Backpropagation}

Neural Network atau biasa disebut Jaringan syaraf tiruan (JST) didefinisikan sebagai suatu sistem pemrosesan informasi yang mempunyai karakteristik menyerupai jaringan syaraf manusia (Hermawan, 2006). Beberapa istilah dalam JST yang sering ditemui adalah sebagai berikut.

a. Neuron atau node atau unit: sel syaraf tiruan yang merupakan elemen pengolahan jaringan syaraf tiruan. Setiap neuron menerima data input, memproses input tersebut kemudian mengirimkan hasilnya berupa sebuah output.

b. Jaringan: kumpulan neuron yang saling terhubung dan membentuk lapisan. Lapisan tersembunyi (hiddenlayer): lapisan yang tidak secara langsung berinteraksi dengan dunia luar. Lapisan ini memperluas kemampuan jaringan syaraf tiruan dalam menghadapi masalahmasalah yang kompleks.

c. Input: sebuah nilai input yang akan diproses menjadi nilai output.

d. Output: solusi dari nilai input.

e. Bobot: nilai matematis dari sebuah koneksi antar-neuron.

f. Fungsi aktivasi: fungsi yang digunakan untuk meng-update nilai-nilai bobot per-iterasi dari semua nilai input.

g. Fungsi aktivasi sederhana adalah mengalikan input dengan bobotnya dan kemudian menjumlahkannya (disebut penjumlahan sigma) berbentuk linier atau tidak linier dan sigmoid.

h. Paradigma pembelajaran: bentuk pembelajaran, supervisedlearning, atau unsupervisedlearning.

\subsection{Algoritma Pelatihan}

Menurut Siang (2009:102), algoritma pelatihan untuk jaringan dengan satu layer tersembunyi (dengan fungsi aktivasi sigmoid biner) adalah sebagai berikut.

Langkah 0 : Inisialisasi semua bobot dengan bilangan acak kecil.

Langkah 1 : Jika kondisi penghentian belum terpenuhi, lakukan langkah 2-9.

Langkah 2 : Untuk setiap pasang data pelatihan, lakukan langkah 3-8.

Fase I : Propagasi Maju

Langkah 3 : Tiap unit masukan menerima sinyal dan meneruskannya ke unit tersembunyi diatasnya.

Langkah 4 : Hitung semua keluaran di unit tersembunyi $z_{j}(j=1,2, \ldots, p)$.

$z_{-} n \theta t_{j}=v_{j 0} \sum_{i=1}^{n} x_{i} v_{j i}$ $z_{j}=f\left(z_{-}\right.$net $\left._{j}\right)=\frac{1}{1+e^{-z_{-} \text {net }_{j}}}$

Langkah 5 : Hitung semua keluaran jaringan di unit $y_{k}(k=1,2, \ldots, m)$.

$y_{-}$net $_{k}=w_{k 0} \sum_{j=1}^{p} z_{j} w_{k j}$

$y_{k}=f\left(y_{-}\right.$net $\left._{k}\right)=\frac{1}{1+e^{-y_{2} \text { net }_{k}}}$

Fase II : Propagasi Mundur

Langkah 6 : Hitung faktor $\delta$ unit keluaran berdasarkan kesalahan di setiap unit keluaran $y_{k}(k=$ $1,2, \ldots, m)$

$\delta_{k}=\left(t_{k}-y_{k}\right) f\left(y_{\text {net }_{k}}\right)=\left(t_{k}-y_{k}\right) y_{k}\left(1-y_{k}\right)$

$\delta_{\mathrm{k}}$ merupakan unit kesalahan yang akan dipakai dalam perubahan bobot layer di bawahnya (langkah 7).

Hitung Hitung suku perubahan bobot $w_{k j}$ (yang akan dipakai nanti untuk merubah bobot $w_{k j}$ ) dengan laju percepatan $\alpha$.

$\Delta w_{k j}=\alpha \delta_{k} k_{j} ; k=1,2, \ldots, m ; j=0,1_{m \ldots}, p$

Langkah 7 : Hitung faktor $\delta$ unit tersembunyi berdasarkan kesalahan di setiap unit tersembunyi $z_{j}(j=1,2, \ldots$,

$$
\delta_{-} n \theta t_{j}=\sum_{k=1}^{m} \delta_{k} w_{k j}
$$

Faktor $\delta$ unit tersembunyi

$\delta_{j}=\delta_{-}$net $_{j} f^{\prime}\left(z_{-}\right.$net $\left._{j}\right)=\delta_{-}$net $_{j} \mathrm{z}_{j}\left(1-\mathrm{z}_{j}\right)$

Hitung suku perubahan bobot $v_{j i}$ (yang dipakai nanti untuk merubah bobot $v_{j i}$ )

$$
\Delta v_{j i}=\alpha \delta_{j} x_{i}, j=1,2, \ldots, p ; i=0,1_{w}, n
$$

Fase III: Perubahan Bobot

Langkah 8 : Hitung semua perubahan bobot Perubahan bobot garis yang menuju ke unit keluaran

$w_{k j}($ baru $)=w_{k j}($ lama $)+\Delta w_{k j} x \quad k=1,2, m, m ; j=0,1_{, m}, p$

Perubahan bobot garis yang menuju ke unit tersembunyi

$$
v_{j 1}(\text { baru })=v_{j 1}(\text { lama })+\Delta v_{j 1}(j=1, \ldots, p ; j=1,2, \ldots, n)
$$

Setelah pelatihan selesai dilakukan, jaringan dapat dipakai untuk pengenalan pola. Dalam hal ini, hanya propagasi maju (langkah 4 dan 5) saja yang dipakai untuk menentukan keluaran jaringan. Apabila fungsi aktivasi yang dipakai bukan sigmoid biner, maka langkah 4 dan 5 harus disesuaikan. Demikian juga turunannya pada langkah 6 dan 7 . 
Beberapa kasus pelatihan yang dilakukan memerlukan iterasi yang banyak sehingga membuat proses pelatihan menjadi lama. Untuk mempercepat iterasi dilakukan dengan parameter $\alpha$ atau laju pemahaman. Nilai $\alpha$ terletak antara 0 dan $1(0 \leq \alpha \leq$ 1). Jika harga $\alpha$ semakin besar, maka iterasi yang dipakai semakin sedikit. Hal ini menyebabkan pola yang sudah benar menjadi rusak sehingga pemahaman menjadi lambat.

Dalam standar backpropagation, bobot dan bias diisi dengan bilangan acak kecil dan biasanya bobot awal diinisialisasi secara random dengan nilai antara -0,5 sampai 0,5 (atau -1 sampai 1 atau interval yang lainnya) (Amin, 2012).

\section{Metodologi Penelitian}

\subsection{Teknik Pengumpulan Data}

Dalam menyelesaikan penulisan ini, teknik pengumpulan data yang dilakukan adalah sebagai berikut:

\subsection{Penelitian Pustaka}

Mempelajari, mendalami, dan mengutip teoriteori atau konsep-konsep dari sejumlah literatur, baik buku, jurnal, majalah koran atau karya tulis lainya yang relevan dengan topik fokus atau variable lainnya.

\subsection{Penelitian Lapangan}

Melakukan pengamatan langsung ke lapangan (observasi). Tahap ini diperlukan dalam penerapan sistem yang akan dibangun, dengan tujuan untuk memperoleh data dan informasi yang berkaiyan dengan sistem yang akan penulis kembangkan.

\subsection{Dokumentasi}

Melakukan pengumpulan data-data yang berkaitan dengan penelitian ini berupa data hasil medis pasien serta struktur organisasi,visi dan misi dari lokasi penelitian.

\subsection{Temuan Data}

Data yang diperoleh berupa hasil tes darah di instalasi lanoratorium patologi klinik RSUD Kota makassar. Karena data berupa hasil medis maka banyak variabel yang tidak ada hubungannya dengan penelitian, maka dari itu data disederhanakan sesuai kebutuhan penelitian.

\section{HASIL DAN PEMBAHASAN}

Pengujian system dilakukan untuk menguji semua elemen perangkat lunak yang telah di buat apakah sesuai dengan yang di harapkan.

Untuk memulai aplikasi identifikasi pasien berisikodislipidemia dapat dimulai pada jendela command window dalam aplikasi MATLAB, dengan memanggil dan menginput "JST_Dislipidemia" pada prompt command dan di ikuti dengan menekan ENTER untuk eksekusi fungsi. Dapat dilihat pada gambar 1

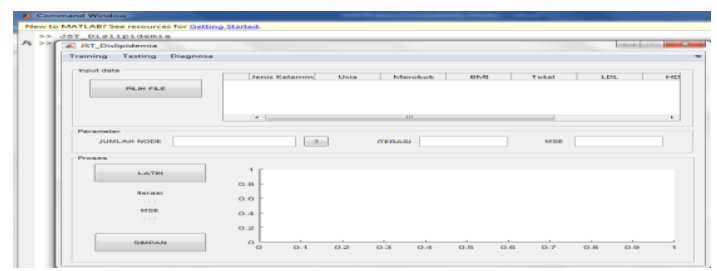

Gambar 1 Pemanggilan Aplikasi pada Command Window

\section{a. Menu Training}

Menu training merupakan menu yang digunakan untuk melakukan pelatihan terhadap $80 \%$ dari 346 data pasien dislipidemia yang telah dilakukan normalisasi data. pelatihan data training digunakan mendapatkan model (hasil training) yang akan digunakan padasaat pengujian datatesting.

Pada saathalaman menu trainingrunning, ada pilihan tombol pilih file untuk memilih file yang akan di training. Setelah melakukan proses pilih file, maka harus mengisi parameter (jumlah node, max iterasi, dan min MSE) kemudian tekan tombol latih. Apabila sudah mendapatkan jumlah MSE yang bagus (mendekati jumlah min MSE yang diinginkan) silahkan tekan tombol simpan untuk menyimpan hasil training. Seperti yang dapat dilihat pada gambar 2 .

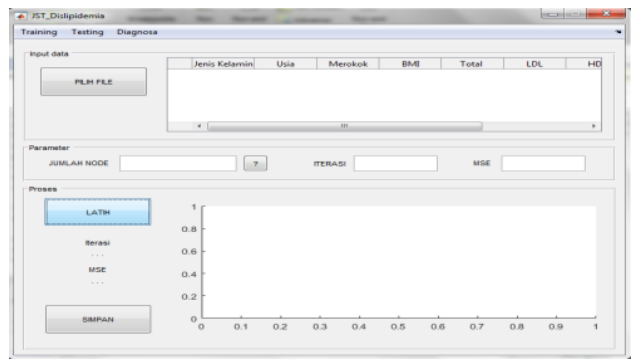

Gambar 2 Form Menu Training

\section{b. Form Menu Testing}

Menu testing merupakan menu yang digunakan untuk melakukan pengujian terhadap 20\% sampel data (data testing) dari 346 sampel pasien dislipidemia yang telah dilakukan normalisasi data. Pada saat halaman menu testing running, ada pilihan seperti tombol pilih file untuk memilih file yang akan di testing. Setelah melakukan proses pilih file, silahkan tekan tombol pilih model untuk memilih model (hasil training), kemudian tekan tombol uji untuk melakukan pengujian terhadap data testing. Seperti yang dapat dilihat pada gambar 3 .

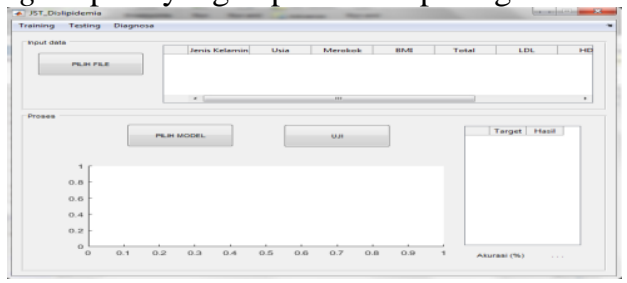

Gambar 3 Form Menu Testing

c. 


\section{Menu Diagnosa}

Menu diagnosa merupakan menu yang digunakan untuk melakukan identifikasi terhadap pasien. Pada saat halaman menu diagnosa running, ada beberapa inputan yang harus diisi sebelum melakukan diagnosa seperti; Jenis Kelamin, Usia, Merokok, BMI, Kolesterol Total, HDL, LDL, dan Trigiliserida.Setelah itu tekan tombol diagnosa, dan apabila ingin melakukan diagnosa lagi, tekan tombol reset. Seperti yang dapat dilihat pada gambar 4

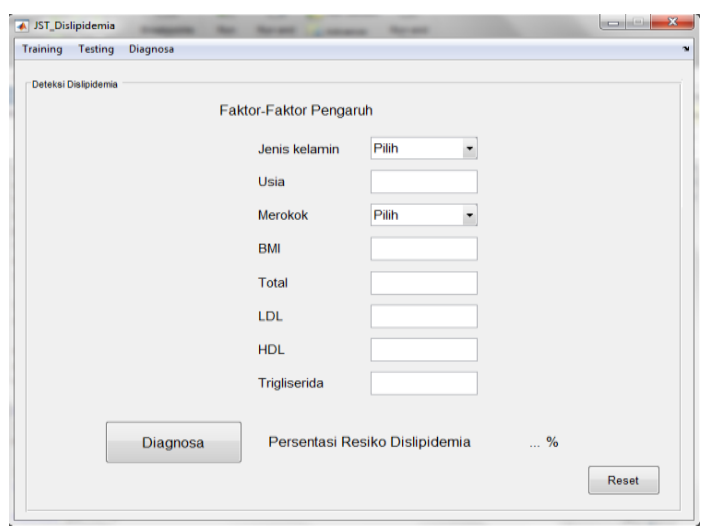

\section{Gambar 4 Form Menu Diagnosa}

Berikut adalah script untuk melakukan penyimpanan hasil dari pelatihan terhadap data training yang terdapat pada table1.

\section{function simpan_Callback(hObject, eventdata, handles) \\ datacontainer $=$ getappdata $\left(0,{ }^{\prime}\right.$ datacontainer $)$; model $=$ getappdata $($ datacontainer, 'model' $)$; [file,path] = uiputfile('*.mat', 'Simpan Model'); save(file, 'model');}

\section{Pengujian Data Training}

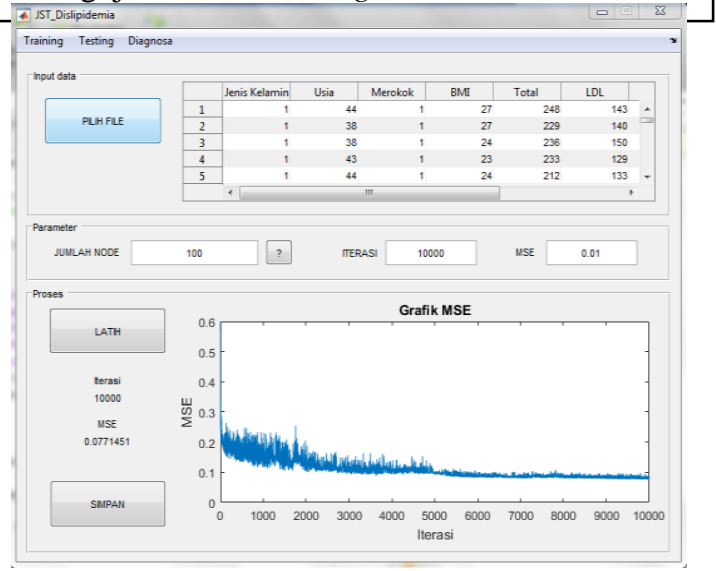

Gambar 4 Pengujian Data Training

Pengujian Data Testing

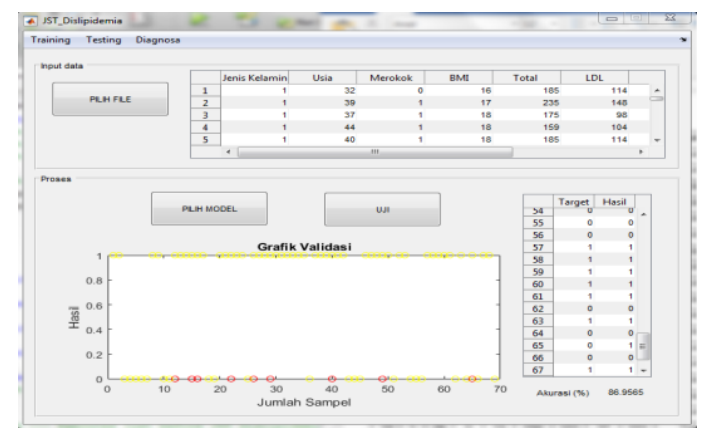

Gambar 6 Pengujian Data Testing

Berikut adalah script untuk melakukan identifikasi terhadap inputan parameter faktor-faktor pengaruh dislipidemia pada pasien.

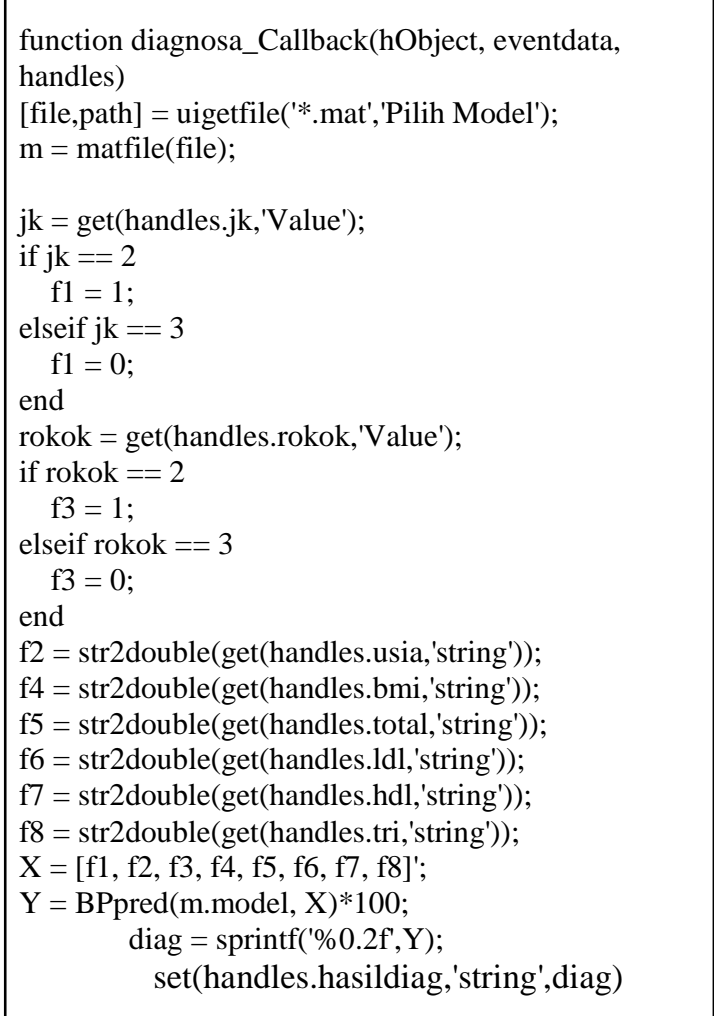

Pengujian Diagnossa Pasien

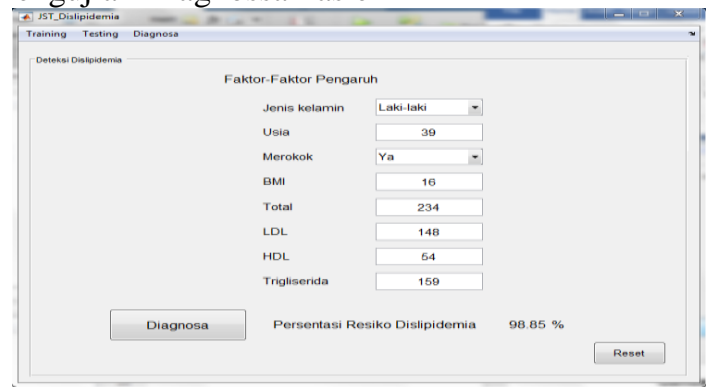

Gambar 7 Pengujian Diagnosa Pasien

\section{KESIMPULAN}

Dari pengujian pelatihan data menggunakan 277 data training (80\%) merupakan data hasil pemeriksaan pasien yang dipilih secara acak untuk 
mendapatkan model training yang akan digunakan saat pengujian data testing.

Pada pengujian data menggunakan 69 data testing (20\%), didapatkan hasil akurasi sebesar $86,96 \%$. Sehingga metode jaringan syaraf tiruan backpropagation untuk mengidentifikasi pasien berisiko dislipidemia layak diterapkan.

Ucapan Terima Kasih

Ucapan terima kasih kepada Kepala Rumah Sakit Umum Daerah Kota Makassar, Jalan Perintis Kemerdekaan KM.14, Kel. Daya, Kec. Biringkanaya, Kota Makassar, Sulawesi Selatan, sebagai tempat pengambilan data.

\section{Daftar Pustaka}

Artikel Ilmiah

Halim, Aldhi, dkk. 2004. Analisis dan Perancangan Pengenal Tanda Tangan dengan Jaringan Syaraf Tiruan Metode Propagasi Balik. Skripsi. Jakarta. Universitas Bina Nusantara.

Hartono, Ahmad Farid. 2012. Implementasi Jaringan Syaraf Tiruan Backpropagation sebagai Sistem Pengenalan Citra Daging Sebagai Upaya Mengenali Daging Sapi Asli dan Daging Sapi Palsu di Pasar Tradisional Kota Semarang. Skripsi. Semarang: FMIPA Universitas Negeri Semarang.

Lestari, M. 2014. Penerapan algoritma Klasifikasi Nearest Neighbor $(K-N N)$ untuk mendeteksi penyakit jantung.Faktor Exacta ISSN : 1979-276X, vol. 7, no. 4, pp. 366-371.

PERKI. 2013.Pedoman Tatalaksana Dislipidemia. Jakarta: Centra Communications.

Ma'rufi, R. dan Rosita, L. 2014. Hubungan dislipidemia dan kejadian penyakit jantung koroner.JKKI, vol. 6, no. 1.

Nurkhozin, Agus, dkk. 2011. Komparasi Hasil Klasifikasi Penyakit Diabetes Mellitus Menggunakan Jaringan Syaraf Tiruan Backpropagation dan Learning Vector Quantization. Surabay. Institut Teknologi Sepuluh November Surabaya.

Puspita, A. \& Eunike. 2007. Penggunaan Jaringan Syaraf Tiruan MetodeBackpropagation untuk Memprediksi Bibir Sumbing. Seminar NasionalTeknologi.

Buku :

Hermawan, A. 2006. Jaringan Syaraf Tiruan, Teori, dan Aplikasi. Yogyakarta:ANDI.

Hidayatullah dan Kawistara. 2014. Pemrograman WEB | HTML CSS | JavaScript |Power Designer|XAMPP | MySQL | PHP | Codelgnitter | Jquery. Bandung : Informatika

Kasiman, Peranginangin. 2006.Aplikasi Web dengan PHP dan Mysql. Yogyakarta: Andi.

Puspitaningrum, D. 2006. Pengantar Jaringan Syaraf Tiruan. Yogyakarta: ANDI.

Siang, J.J. 2009. Jaringan Syaraf Tiruan dan Pemrogramannya Menggunakan MATLAB. Yogyakarta: ANDI 